Entrevista

\title{
Hablemos de Autonomía en Wallmapu: Conversación con el historiador Mapuche Sergio Caniuqueo Huircapan*
}

\author{
Pedro Canales Tapia ${ }^{* *}$
}

Si articulamos un análisis histórico de la situación actual que vive la Araucanía: violencia, muerte y represión sistemática contra comuneros mapuche, en un contexto en el que desde la oficialidad se acusa la existencia de grupos terroristas (mapuche) en dicha región, tenemos que ser capaces de abrir el debate y barajar ideas que permitan comprender la singularidad y gravedad de lo que sucede en dicho espacio.

Dicho de otra manera, podemos consignar que este cuadro de violencia es un libreto conocido. El estado chileno inauguró esta violencia con la ocupación militar del antiguo territorio mapuche; "redujo" a los sobrevivientes en retazos de su otro gran territorio; entregó tierras a colonos extranjeros y chilenos ${ }^{1}$, e inauguró con esto, o mejor dicho, proyecto una ideología racista y colonialista que perdura hasta nuestros días 2 .

En este escenario, el trabajo y la voz del historiador mapuche Sergio Caniuqueo se hace necesaria y perentoria hoy por hoy. Es tiempo de ir re-definiendo tópicos de la historia, tejiendo nuevos puntos y enhebrando otros hilos. Los puntos que permiten vislumbrar en parte el sitio desde donde se erige este investigador, se puede resumir en el siguiente párrafo.

“(...) nací en Temuco -indica Caniuqueo-, mis dos papas son del campo (...); mi mama se crió en el sector de Malarche en Cholchol; bueno mi papa

\footnotetext{
${ }_{* *}^{*}$ Este trabajo se inserta dentro del proyecto FONDECYT N ${ }^{\circ} 11121231$.

** Chileno. Doctor. Post doctorado. Instituto de Estudios Avanzados. Universidad de Santiago de Chile. Académico Universidad Viña del Mar. E mail: pedro.canales@usach.cl; pcanales@uvm.cl

${ }^{1}$ Pinto, Jorge (2015). La Formación del estado y Pueblo Mapuche. De la inclusión a la exclusión. Santiago: IDEA-USACH.

${ }^{2}$ Mariman, Pablo et al (2006). iii... Escucha, winka...!!! Cuatro ensayos de historia nacional mapuche y un epilogo de futuro!!! Santiago: Ediciones Lom. En este libro sus autores sostienen que la literalidad de este texto es un grito de toma de conciencia, pues el colonialismo no sólo opera sobre la población mapuche sino que también sobre la población chilena en general.
} 
tiene una historia de migración, de Nueva Imperial, luego Temuco, después Santiago, y ya a los 24, 25 años decide volver a Temuco a rehacer su vida a asentar cabeza, por lo que él me dice; y en el caso de mi mamá, ella trabajaba de empleada doméstica y también trataba de sacar su enseñanza media (...)

Añadiendo:

“(..) mi papa también estaba con ese interés, se conocieron en el liceo comercial, acá en Temuco; en ese tiempo el liceo comercial era vespertino, básicamente tomaban cursos en la noche, entonces ahí se conocieron; nací yo, mi hermana acá en Temuco, bueno y acá mucha familia no teníamos, entonces teníamos más relación con la familia del campo, entonces básicamente puedo decir que soy un mapuche urbano, pero podría decirte que soy un mapuche urbano de primera generación por darte una categoría"3.

La ruralidad y el espacio urbano, así como a mucha población mapuche, marcaron la mirada y la elaboración discursiva de Sergio Caniuqueo a la hora de iniciar su trabajo historiográfico. Un mapuche urbano en palabras de José Ancan'; un Mapurbe en la letra de David Añiñir ${ }^{5}$. Con estudios en la Universidad de La Frontera de Temuco y posteriormente en la Universidad de Chile en la ciudad de Santiago, Caniuqueo detenta entre otros "galardones" ser considero el "(...) con más porvenir" entre los jóvenes historiadores mapuche que están destacando actualmente en palabras de Jorge Pinto ${ }^{6}$. Más allá de este halago, este investigador se ha constituido como un referente calificado y respetado entre mapuche y no mapuche que estudian la historia de la Araucanía y de una u otra forma, la historia mapuche.

Los trabajos más destacados de Sergio Caniuqueo parten con su participación en el libro Escucha winka junto a Pablo Mariman, José Millalen y Rodrigo Levil, trabajo del año 2006 que fue un punto de cierre y de apertura a la vez de lo que podríamos denominar pensamiento mapuche historiográfico ${ }^{7}$. El capítulo escrito por Caniuqueo se denomina El siglo XX en Gulumapu, en el cual pone el acento en el

\footnotetext{
${ }^{3}$ Se agradece al profesor Mathias Ordenes por el registro y trascripción de esta entrevista.

4 Ancan, José (1994). "Los urbanos: Un nuevo sector dentro de la sociedad mapuche contemporánea", Pentukun 1. Temuco: Instituto de Estudios Indígenas, Universidad de la Frontera.

${ }^{5}$ Añiñir, David (2009). Mapurbe/Venganza a raíz. Santiago: Pehuén ediciones.

${ }^{6}$ Canales, Pedro (2015). Historiografía Mapuche: balances y perspectivas de discusión en el Chile reciente. Conversación con Jorge Pinto Rodríguez. Revista Izquierdas N² 24. IDEA-USACH. p. 236.

${ }^{7}$ Mariman, Pablo et al. Op. cit.
} 
proceso de unidad nacional mapuche experimentado entre 1880 y $1978^{8}$. En otros momentos a consignado que “(...) la reconfiguración del colonialismo chileno se debe al cambio estructural del País-Estado, en la cual se debe considerar la tensión existente entre un centro y una periferia9; el año 2011 sostuvo que la matriz cultural era un punto clave en la elaboración de discursos y proposiciones en contextos de post ocupación de territorio mapuche ${ }^{10}$; el 2013 profundiza en la reconfiguración que la dictadura militar hizo del colonialismo en Chile ${ }^{11}$; sosteniendo recientemente en el libro Zuamgenolu, que el grupo de teatro Tacum, iniciada la década de 1980, fue parte de una nueva arista en la historia mapuche, toda vez que “(...) Ad-Mapu debió incorporar nuevas reivindicaciones a su programa político y reimpulsó su lucha opositora a la dictadura militar"12.

Hoy que la discusión se concentra en lo que se ha dado a llamar "conflicto mapuche", "violencia en la Araucanía" y "terrorismo" en las antiguas tierras de la frontera, es necesario abordar en propiedad una de las demandas más potentes y a la vez complejas en el movimiento mapuche. Iniciados los años 90, José Mariman presentó a la opinión pública un trabajo referido a "autonomía regional" de ahí en más son varias las propuestas, incluyendo recientemente la de Francisco Huenchumilla y su estado plurinacional ${ }^{13}$, que se han jugado por trabajar en ideas y medidas concretas en torno al problema de la tierra y la territorialidad, el sueño de la autonomía según muchos. En este sentido, Huenchumilla marca tres tareas en relación a los pueblos indígenas: “(...) sinceramiento y reconocimiento; una política de reparación y un cambio cultural en el país"14.

El debate de la que da cuenta Sergio Caniuqueo es una construcción semántica y política que tiene una base argumentativa de doble entrada, por un lado, la historia "larga" del pueblo mapuche es una elaboración-devenir sellado por nociones como libertad y autonomía. El hito de 1641 en Quillin -parlamento en el cual el gobernador de Chile, el Marqués de Baides, firmó la autonomía mapuche al sur del río Bío Bío-, abre las compuertas y proyecta la historicidad de este pueblo en

\footnotetext{
${ }^{8}$ Caniuqueo, Sergio (2006). El siglo XX en el Gulumapu: de la fragmentación del Wallmapu a la unidad nacional mapuche. 1880-1978 En Mariman, Pablo et al. Op. cit.

${ }^{9}$ Caniuqueo, Sergio (2013). Dictadura y pueblo mapuche 1973 a 1978. Reconfiguración del 89 colonialismo chileno. Revista de Historia social y de las mentalidades. USACH. $\mathrm{N}^{\circ}$ 16. p. 90.

${ }^{10}$ Caniuqueo, Sergio (2011). Reflexiones sobre el uso de la cultura como matriz cultural en el caso Mapuche. Algunas notas introductorias de principios del siglo XX. Cuadernos interculturales. $\mathrm{N}^{\circ}$ 17. UV. pp. 75-76.

${ }^{11}$ Caniuqueo, Sergio (2013). Reconfiguración del colonialismo. Revista historia social y de las mentalidades. $\mathrm{N}^{\circ} 17$. USACH.

${ }^{12}$ Caniuqueo, Sergio (2016). Tacum. El grupo de teatro de Ad-Mapu. En Canales, Pedro. Zuamgenolu. Pueblo mapuche en contexto de estado nacional chileno. Siglos XIX-XX. Santiago: Ediciones Usach. p. 181.

${ }^{13}$ Huenchumilla, Francisco (2017) Plurinacionalidad. El nuevo pacto. Santiago: Pehuén ediciones.

14 Ibíd: 25.
} 
contexto autonómico; por otro lado, en el siglo $\mathrm{XX}$, más precisamente iniciada la década de 1930, un dirigente mapuche emblemático de esos años, Manuel Aburto Panguifel de Loncoche, arengaba en pos de la fundación de lo que él denominó "republica indígena". La historia del movimiento mapuche es la historia por la autonomía. Los diputados mapuche entre 1924 y 1973, entre ellos Manquilef, Romero, Cayupi, Coñoepan y Huenuman, pensaron y debatieron en esta clave y sobre este soporte.

Así visto el panorama temporal en la "larga" historia mapuche, la autonomía es parte elemental de los procesos históricos mapuche. No es casualidad, en este sentido, que el canto mapuche, la memoria de los ancianos y otras evidencias, dejen entre ver esta condición. En el detalle de estas expresiones, la añoranza de un pasado en libertad, en abundancia económica y bajo los márgenes convivenciales marcados por el Ad-Mapu, las leyes mapuche, son una evidencia, pero también son expresión concreta de los debates que hoy se dan respecto de autonomía, autodeterminación y descolonización.

\section{Entrando al debate}

Desde la década de 1990 en adelante se ha visto con creciente nitidez la participación de población indígena en foros y debates referidos al pasado, al presente y futuro de estos pueblos. Por ejemplo, en 1994 José Mariman publicó uno de los primero trabajos acerca del debate por la autonomía ${ }^{15}$. Veinte años después, Tito Tricot escribe también al respecto. Las Ciencias Sociales en Chile se han ido dando a la tarea de debatir en torno a este concepto ${ }^{16}$. En este mismo escenario, Claudia Zapata, a un grupo de estos(as) interlocutores, los ha denominado, intelectuales indígenas ${ }^{17}$, categoría que ha permitido elaborar diálogos pero también tensiones entre quienes hacen el ejercicio de conceptualizar y quienes son los categorizados ${ }^{18}$. En este sentido, Sergio Caniuqueo es parte de esta discusión y es representante de -como indicamos el líneas precedentes- un interesante trabajo historiográfico a lo largo de los últimos veinte años. Desde este hilo orientador iniciamos la conversación.

Cuéntenos a que se encuentra avocado en cuanto a estudios, investigaciones se refiere

\footnotetext{
${ }^{15}$ Mariman, José (201X). Autoderminación. Santiago: Lom.

${ }^{16}$ Tricot, Tito (2012). Autonomía. El Movimiento Mapuche de Resistencia. Santiago: Ceibo Ediciones.

${ }^{17}$ Zapata, Claudia (2007) Intelectuales indígenas piensan América Latina. Quito: Abya Yala.

18 Ver Canales, Pedro (2012). "Intelectualidad mapuche, problemáticas y desafíos. Conversación con el historiador José Marimán Quemenado”. Revista Cuicuilco, Núm 63, México: Escuela Nacional de Antropología e Historia. p. 223; Canales, Pedro (2014) Etno intelectualidades. Revista Aplha. N N $^{\circ}$. ULA.
} 
(....) analizando básicamente el periodo de la dictadura militar, y como la dictadura militar reconfiguro el sistema colonialista chileno, articulado también, justamente el neoliberalismo, entonces estoy trabajando sobre eso, estoy acotando en dos organizaciones que uno es el consejo regional mapuche y el otro es el comité exterior; porque en el fondo, lo que yo postulo dentro de esta tesis, es que en el fondo el colonialismo es un elemento cultural que trasciende simplemente a las poblaciones políticas, las personas portan la ideología colonial, esa ideología colonial se puede dar acá en la novena región, como se puede dar a miles de kilómetros, como puede haber sido en Europa, con el caso de los exiliados mapuche frente a los exiliados chilenos, y uno ve como esta lógica colonial subalterniza todo el rato al sujeto colonizado, que en este caso, es el mapuche.

Entonces ir trabajando esos dos casos de manera comparativa, haciendo un trabajo más historiográfico, pero también trabajando con algunos elementos de la memoria y con esos elementos de la memoria básicamente el tema de la representación, o sea, como los sujetos se representan, como representan al régimen, $\mathrm{y}$ ha sido

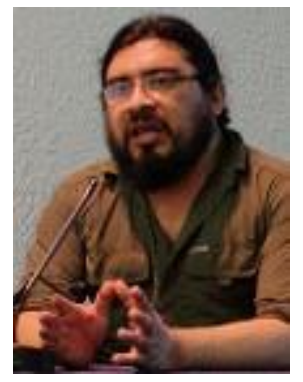
bastante interesante, porque en el fondo, son dos agrupaciones, que no han sido estudiadas por la mayoría de los intelectuales chilenos y tampoco mapuche, entonces es un trabajo que ya lo estoy finalizando, estoy elaborando el ultimo capitulo y posterior a eso estoy haciendo el doctorado en estudios latinoamericanos y voy a seguir con este tema digamos con la dictadura y la relación con el pueblo mapuche, pero ahora abarcando más actores y más situaciones, ampliando también las redes de relaciones que surgen dentro del colonialismo, las redes de relaciones se da tanto hacia el lado de la derecha como hacia el lado de la izquierda, y también hay una capacidad de respuesta desde el propio pueblo mapuche hacia este fenómeno colonial, esa capacidad de respuesta va desde los pactos con el régimen pero no son pactos que son, podríamos decir, que no son pactos sin nada a cambio, o sea son pactos en la cual están condicionados y a ratos también se vuelven pactos problemáticos también.

Básicamente a futuro voy a enfocarme en ese tipo de relaciones, y bueno esperemos que de aquí a cuatro años tengamos una visión mucho más clara y también está el tema de ir publicando lo que voy encontrando, he tenido harto trabajo de archivo, trabajo de fuente orales, mucha lectura teórica también, entonces básicamente estoy en eso, estoy en ese tema de procesos, y paralelo a ello estoy coordinando un taller de descolonización con chicos que están saliendo de la carrera de historia, es voluntario y está integrado por gente mapuche y no mapuche, eso básicamente. 


\section{Una pregunta elemental y necesaria ¿Por qué escribe historia del pueblo mapuche?}

Creo que tiene que ver un poco con la crianza; mi abuelo, mi abuela, mi bisabuela principalmente, yo a mis abuelos los vine a conocer muy tarde, pero mi bisabuela siempre contaba historias que después mi mama traducía, porque ella era monolingüe, no hablaba castellano prácticamente, entonces siempre la historia que ella cuenta en relación a los chilenos, es una historia dolorosa, pero aparte no encajaba con lo que a uno le enseñaban en el colegio, entonces era una historia disociada, disociada de esta historia nacional que uno ve escolarmente, entonces se me fueron acumulando preguntas, y bueno en algún momento había que darle salida a eso, y cuando tuve la posibilidad de estudiar historia, me di cuenta que tampoco las respuestas estaban dentro de la investigaciones que existían, a un nivel más profesionalizado, claro habían cosas que se habían ido trabajando desde el pueblo mapuche, pero quedaba y queda todavía mucho paño por cortar en ese aspecto.

Para mí la investigación nace desde mi seno familiar, mi idea de ir trabajando el tema de historia, yo creo que si no hubiera estudiado historia, igual me hubiera dedicado de alguna forma a la historia , o sea, tiene que ver un poco con la imagen que tú te vas construyendo del otro que es una imagen igual cargada de imaginarios de aspectos tanto positivos como muy negativos, entonces finalmente todo esto me empujo a mí a dedicarme al tema de la historia, tuve las posibilidades también, y eso también creo que puede ser lo anecdótico o sea, yo entre a trabajar al archivo regional y tuve acceso a un montón de material de manera muy temprana, entonces eso también me sirvió bastante para mis investigaciones, y también gracias a ello he podido tomar cursos de archivística, lo que me ha permitido ir profesionalizando mi investigación, aparte he tenido un circuito intelectual tanto mapuche como no mapuche, que me ha permitido a mi acceder a un montón de lecturas, libros, ya he accedido a lectura, mucha lectura que acá en Chile prácticamente ni se trabaja.

Entonces he tenido en términos anecdóticos una fortuna digamos, una fortuna en la cual he podido converger con distintos tipos de conocimientos y eso sumado también a las relaciones de amistad y a la participación política sobre todo en este tipo de relaciones, que son la amistad y las relaciones políticas, uno también genera una gran cantidad de aprendizaje que no lo puede desarrollar vía lectura, hay una praxis que a ti te permite poder profundizar, en términos de los conceptos teóricos que puedes leer, entonces tu puedes leer, por ejemplo, a Marx, pero jamás vas a entender a Marx mientras no tengas una militancia y un accionar en esa vía, o sea, 
vas a entender teóricamente y vas a visualizar teóricamente algunos aspectos pero jamás vas a poder llegar a generar un conocimiento cabal mientras no hayas recorrido ese camino, y eso básicamente uno lo ve en los historiadores que jamás han militado en nada y por ejemplo quieren trabajar esos temas y les cuesta procesarlos.

Por en ese camino uno también va esclareciendo las problemáticas que tuvieron teóricamente para resolver ciertos temas; entonces ahí también el papel de la imaginación juega mucho en cómo resolver situaciones, situaciones concretas, entonces eso a mí me ha permitido ir desarrollando una visión bastante crítica sobre la historia mapuche también, o sea, yo no escribo una historia mapuche condescendiente con la sociedad mapuche, yo escribo una historia mapuche en la cual investigo, analizo los puntos críticos, los puntos críticos que tiene la propia cultura, y en base a eso escribo, entonces tampoco, si bien es una historia comprometida políticamente, no es una historia que busca desarrollar un populismo que esta tan de moda, como el populismo de izquierda, no, yo me trato de desmarcar un poco de esos populismos, y trato de ver qué aspectos concretos se pueden realizar, y por eso recurro a la historia entonces.

Hay un proyecto político de por medio, entonces básicamente es lo que a mí me lleva a escribir historia, que me permita generar análisis reflexivo, resolver preguntas teóricas-practicas, generar una praxis política, entonces son todos esos elementos unidos, y también está eso de cómo vas a conocer lo que investigas, que no necesariamente debe ser un paper, ósea, yo trabajo con un montón de talleres, y lo que menos uno ve es un paper, hay mucho trabajo también político, que tiene que ver en reproducir aspectos de la oralidad o entregar información, o devolver papeles a alguna comunidad por ejemplo que es lo que uno hace.

En este sentido, ¿Cuáles son sus objetivos, metas en este camino del cual nos habla?

En el fondo yo creo que cualquier proyecto político necesita de un pasado, y ese pasado necesita ser bien descrito, bien reflexionado, bien critico de ese pasado, creo que esa historia demasiado ideológica respecto al pueblo mapuche, así como que el pueblo mapuche sea prácticamente una sociedad perfecta y en el fondo no sirve mucho, ósea te hace caer en una serie de esencialismos que en el fondo no te construyen a nada, y por lo tanto en el fondo, juegan también un papel de alineación, o sea en este caso los dos sectores te alienan, o sea uno, decir que tu sociedad, es una sociedad incivilizada y por lo tanto necesita de la modernidad y dentro de esa modernidad tu blanqueas tu sociedad, también es una alineación, y está este otro punto que es la alineación por la vía del esencialismo, así como que 
esto es una sociedad perfecta y vinieron los huincas y eso nos hecho a perder como sociedad, ambos generan dos polos sumamente dicotómicos pero al mismo tiempo sumamente irreales.

Por lo tanto, son fricciones que se construyen (...) sobre la historia mapuche; entonces mi militancia tiene que ver con eso, o sea, en contribuir a una historia mucho más concreta y que nos permita a nosotros abordar un proyecto político que también sea completo, o sea un proyecto político que también sea concreto, ósea, un proyecto político que movilice a la gente, que nos permita establecer estrategias, que nos permitan establecer puntos de negociación, que nos permita establecer puntos de resistencia, todos esos son puntos que van apareciendo en este análisis histórico y también te da una noción de continuidad de lo que otros han hecho, bueno o malo, pero lo han hecho, entonces también eso es bueno porque también lo colocas en valor, o sea, mucha de la historia mapuche es totalmente episódica, sobre todo lo que tiene que ver con el movimiento.

Cada organización cree que va a inventar la pólvora y como que cada organización quiere partir de cero, eso también es estupidez, ósea no está apegado a la realidad, o sea el movimiento mapuche ha sido, podríamos decir que es un tejido, se ha tejido por distintas organizaciones que todos han contribuido, incluso por organizaciones que han trabajado dentro de un gobierno, todos han contribuido, $y$ entonces ese tejido es el que a mí me gusta relevar, y no los puntos que alcanzo a hacer una organización, yo prefiero ver el paño completo, entonces esa es como mi visión militante también.

Esas dificultades que Ud. percibe, de quien escribe la historia mapuche, siendo mapuche, sea un aspecto cultural, sea una interpretación de una deformación que toman de la academia, por qué ¿de donde nace eso a su juicio?

(...) hoy en día se habla mucho de oralidad, por el movimiento maya pero cuales son las fuentes para hablar acerca de ese pasado milenario indígena, la arqueología, o sea, hablan mucho de oralidad pero en términos concretos están resurgiendo a ciencias digamos que están basadas en la armas científicas como la arqueología, entonces ahí hay un juego entre lo que tú quieres representar en términos discursivos, políticos, y otra cosa es como opera para construir información, ahora mira, yo no es que vea la academia como un elemento nocivo para nosotros, creo que la academia, dentro de la academia también se establecen estos dos puntos digamos que te mencionaba antes, uno entre los académicos que buscan esencializar lo mapuche, tenemos un montón de académicos que dicen no lo mapuche es esto, y te cuentan un cuento pero que realmente no tiene nada que ver con la realidad mapuche. 
Por nombrarte un caso, el artículo de María Ester Greb por ejemplo, yo creo que nadie se ha puesto a pensar porque María Estar Greb escribió ese artículo, pero si uno le diera vuelta, uno se daría cuenta que María Ester Greb cuando escribe ese artículo, ella está disputando poder, entonces tienes por un lado al tipo sumamente pragmático, como Berdichesky digamos en los 70’ antropólogo marxista de excelencia por decirlo así, y por otro lado, tienes a esta señora en la cual hace un juego y te esenciliza la cosmovisión mapuche, te dice, ya esta es la cosmovisión mapuche, de hecho el texto se llama cosmovisión mapuche, y lo interesante es que este texto de cosmovisión mapuche no respeto las identidades territoriales y no respeto los elementos cosmovisionales de cada identidad, o sea, paso por encima de ellos, y hay elementos que ni siquiera sectores mapuche la reivindicarían, pero esa disputa ella no la está haciendo hacia el mundo mapuche sino que hacia el propio mundo chileno.

Dentro de la academia hay juegos de poder en la cual los sujetos les conviene esencializar por ellos aparecen como los únicos traductores de lo mapuche, entonces ahí hay un juego perverso también que muchas veces, o sea el decir mira esto es tan complejo, que solamente los antropólogos o los etnohistoriadores o nosotros que somos tan especialistas, porque somos mapuchologos le podemos descifrar y lo podemos traducir hacia ustedes, entonces hay un poco de la traducción de lo mapuche hacia este otro mundo, pero ahí cuando uno ve eso también se da cuenta de que es un juego de poder y hay un juego de poder en la academia en la que obviamente te tiene que marginar a ti, porque si no le quitas la voz a ellos y no es por casualidad que hoy en día por ejemplo, son muy pocas las universidades que contratan a académicos indígenas para hacer procesos de investigación o procesos de enseñanza del mundo mapuche desde una perspectiva más crítica, ósea hoy en día, tenemos la mayoría de los docentes indígenas condicionados de una u otra forma, ya sea por ejemplo, por el grado que ocupa dentro del escalafón de la universidad, ósea, por las relaciones que tienen con sus pares, ósea, la mayoría de los académicos mapuche están solos y eso no es porque si, ósea, la mayoría de los académicos mapuche están en una situación de inestabilidad laboral y eso no es porque si y los que están en mejor situación, están en una situación de aislamiento académico, por lo tanto, se pueden desarrollar hasta un cierto nivel, hacia un cierto techo, pero esos académicos mapuche que asumen identidad y que asumen el proyecto político es lo más probable que jamás lleguen a ser o rectores o vicerrectores, ósea, hay una parte ahí a la cual también hay un tope, entonces la academia, también reproduce las relaciones coloniales.

Eso es lo que uno tiene que entender también, uno como investigador reconoce que la academia tiene o reproduce los códigos del colonialismo y las estructuras del 
colonialismo y eso es una cuestión que está presente, por eso yo te mencionaba que el colonialismo no es simplemente un tema político-ideológico, no, el colonialismo está inserto en todos los tipos de relaciones humanas, ósea por ejemplo, un tipo que hace el aseo acá, si sabe mi apellido me ha gritar indio, y se va a sentir mejor que yo, entonces eso tiene que ver con el colonialismo, entonces creo que la academia es eso, creo que la academia funciona bajo una estructura colonial, ahora eso nos indica o quiere decir que no sea un espacio donde disputar poder, que no sea un espacio donde generar discusión, que no sea un espacio donde generar reflexión.

Todos los espacios sirven, desde un club de adulto mayor, desde una agrupación de adultos mayores hasta la universidad sirve para eso, ósea, mientras tu tensiones y coloques y devele cuales son relaciones que afectan a chilenos y mapuche que son relaciones racializadas que son relaciones en la cual son relaciones desiguales, en la cual hay construcción de imaginario, y que esta construcción de imaginario no solo se sustenta en las ideas, sino también en bases materiales, que van desde aspectos laborales, que van desde los aspectos económicos, es un edificio que se construye, y eso es lo que uno hace en estos juegos.

Ud. recién señalaba que una de sus metas es liberar el conocimiento mapuche, la historia mapuche, desde lo que se ha hecho incluso dentro del pueblo mapuche, de los intelectuales mapuche pero dentro de la academia, controlando el conocimiento, y tu objetivo sería la liberación de ese conocimiento.

No solamente la liberación del conocimiento, o sea, la liberación en todos los aspectos, políticos, económicos, y dentro de ellos el conocimiento juega un papel fundamental, ósea, el conocimiento es lo que te puede dar legitimidad, a lo mejor, por ejemplo, tu puedes tener la legitimidad pero no la legalidad, ósea, y esa es una cuestión que la otorga el conocimiento, el conocimiento te puede otorgar legitimidad, las leyes no siempre se hacen con conocimiento, para eso tenemos miles de ejemplos, o con sabiduría, incluso con muy poco conocimiento, ósea, tenemos textos que han sido pegoteos de wikipedia, para fundamentarla, ósea, nivel de conocimiento no hay nada prácticamente. Mira, claro es necesario una liberación a partir de la construcción de conocimiento.

Ahora yo hablo de construcción de conocimiento porque creo que justamente, el conocimiento se construye en base a las relaciones sociales y hoy en día si yo quiero construir de una manera distinta tengo que cuestionar justamente como están estructuradas esas relaciones sociales, y por eso, por ejemplo, a mí me interesa trabajar en el plano interétnico, ósea, en el plano que mi reflexión no solo 
sea escuchado por el lado mapuche sino que por los chilenos, entonces creo firmemente que los procesos de descolonización se deben dar en ambos lados, ósea, la estructura colonial por un lado formatea al que coloniza, y por otro lado formatea al colonizado, entonces tú tienes que volver a formatear esas relaciones, y para eso justamente tienes que criticar como se han estructurado.

Por ejemplo hoy en día tenemos un montón de autores que nos dicen, no es que los mapuche viven más en la espiritualidad, claro pero es cómodo decir eso, porque tú al tiro estableces una categoría de lo que es mapuche y de lo que no es, entonces el mapuche que no es espiritual dejaría de ser mapuche, y si deja de ser mapuche entonces pierde sus derechos como persona dentro del pueblo mapuche, entonces estos esencialismos también operan como lógicas de dominación, entonces por ejemplo cuando un hermano mapuche reproduce que los verdaderos mapuche, son los mapuche que creen en la religiosidad mapuche, está reproduciendo justamente un argumento colonial, entonces esas son los trampas que te genera el colonialismo, pero esas trampas las tienes que hacer discutiendo con los demás.

\section{En este escenario ¿Cuál es su aporte concreto en esa complejidad histórica?}

No creo que uno lo pueda medir así de hasta uno o no llegue; de una manera así tan concreta, creo que estos procesos no lo hace un hombre, creo que siempre he pensado que los procesos de transformación o cambios sociales lo hacen personas común y corrientes, y esa persona común y corriente puede estar a años luz de lo que tu pensaste, ósea, por colocarte un caso en el 71' Lorenzo Ayllapán, el hombre pájaro, como hoy en día se conoce a este poeta, declara que en el fondo el movimiento que libera al pueblo mapuche no va a ser ni de izquierda ni derecha, sino que va a ser un movimiento unificador de la raza o de la nación en un lenguaje más moderno, o más contemporáneo por decirlo, y no se lo dijo hace 40 años atrás, eso te indica que en el fondo las ideas que uno exprese en estos momentos pueden reflejarse en 40 años más, en 50 años más, en 70 años más, en 100 años más, ósea sería demasiado ególatra pensar que nuestro pensamiento va a influir de una manera tan inmediata, creo que fuera de eso porque, porque nuestro pensamiento tiene que, como te explicaba recién con esta metáfora de lo que puede ser un tejido o un paño, ósea, uno contribuye con una hebra más, dentro de un paño, es un trabajo pequeño pero que sustenta el trabajo de otros y que al mismo tiempo el trabajo de uno está sustentado en lo que hizo otro anteriormente, entonces en ese sentido creo que lo que yo haga, puede tener efectos más inmediatos en algunos círculos cercanos, que no van a implicar un cambio decisivo.

\section{En torno a la autonomía}


La construcción de la historia mapuche a partir de los enunciados aquí presente, se ha ido elaborando a partir de propuestas teóricas y metodológicas que marcan la inflexión en nuevas formas de entender a quienes hacen o protagonizan esta historia, y como esta es aprehendida por quienes la estudian, analizan y publican. Frantz Fanon ha sido rescatado en la reflexión mapuche y sus proyecciones autonómicas $^{19}$. También se han presentado con abundancia el pensamiento de Silvia Rivera ${ }^{20}$. En el ámbito mapuche, Héctor Nahuelpan, en este sentido, y su trabajo sobre las "zonas grises" en la historia mapuche21, el trabajo de José Luis Cabrera Llancaqueo 22 o más recientemente de Enrique Antileo y Claudio Alvarado Lincopi, Santiago waria mew ${ }^{23}$, son expresión de esta reflexión, que enmarca su certeza en la historia cotidiana, intercultural, compleja e invisibilizada que ha vivido la población mapuche en los últimos ciento treinta y cuatro años de colonialismo. En este sentido, caben las preguntas acerca de lo que se ha llamado la "unificación" mapuche en su conjunto.

\section{En su opinión, evaluativamente ¿En qué pie se encuentra el proceso de unificación mapuche?}

Creo que en estos momentos, haber no creo que tampoco no exista una unificación, existe un elemento unificador, ósea, yo creo que cuando uno habla de unificación piensa básicamente en esta idea política de que la unificación representa una cierta uniformidad de ideas y de proyectos, ósea siempre pensamos que los proyectos políticos, deben tener una dirección y deben tener también una división social en su interior, ósea, tener líderes, tener ideólogos, tener negociadores, tener operadores políticos y tener la masa, siempre se piensa la política y la unificación en esos términos, que obviamente está centrado en la toma del poder, porque si no sería lo pre político en el lenguaje de Eric Hobsbawm y por lo tanto carecería de una verdadera revolución por decirlo así, en un sentido más marxista.

Existe una unificación en el sentido de que la gente posee una identidad y esa identidad hace que se exprese frente a los chilenos de distintas formas, ahora lo que yo creo que, y esto es lo que yo postulo en términos teóricos, es que lo que tiene el pueblo mapuche dentro de esta cualidad amplia es justamente no es la

\footnotetext{
${ }^{19}$ Fanon, Frantz (2003). Los condenados de la tierra. México: Fondo Cultura Económica.

${ }^{20}$ Rivera, Silvia (1986). Oprimidos pero no vencidos. La Paz: La mirada salvaje.

${ }^{21}$ Nahuelpan, Héctor (2013). Las "zonas grises" en la historia mapuche. Revista de historia social y de las mentalidades. $\mathrm{N}^{\circ} 17$. Dpto. Historia. Usach.

${ }^{22}$ Cabrera Llancaqueo, José L (2013). Machi mongen tani Santiago waria mew. Santiago: grupo de trabajo Kuifike.

${ }^{23}$ Antileo, Enrique y Alvarado, Claudio (2017). Santiago waria mew. Santiago: comunidad de historia mapuche.
} 
homogenización, sino que la heterogenizacion, y claro hay una convergencia mayor en coyunturas políticas y eso es verdad, es lo que uno aprecia a través de la historia, pero que el resto del tiempo es la vida en la heterogeneidad, por lo tanto eso permite que se desarrollen o se articulen una sistema de respuestas, y eso es lo que da cuerpo finalmente al pueblo mapuche, o sea que tiene la capacidad de generar un sistema de respuestas en donde la respuesta puede ir de lo más esencialista hasta lo más modernizador y así se representa la unidad, porque en el fondo cual es la base, modificar las condiciones desde la situación colonial mapuche, ósea, esa es la base finalmente, entonces a nosotros nos hacen creer que estamos todos unidos cuando pensamos todos lo mismo y creemos todos lo mismo y mucha gente lo piensa.

Mucha gente mapuche se compra ese cuento, ósea, que nosotros los mapuche estamos todos desunidos y que en el fondo no estamos unidos porque no vamos todos para un mismo lado, ósea por ejemplo, no todos somos mapuche creyentes (...) y es imposible serlo, porque la fe es algo muy personal, tú no puedes obligar a una persona a tener fe, ósea la fe es un sentimiento interno de la persona y si la persona tiene fe, por ejemplo hay mapuche que son cristianos, que son evangélicos, son evangélicos, católicos, mormones y todo eso, y esos mapuche sienten que esa idea religiosa los representa y se sienten cómodos y conformes, pero ellos no reniegan de esa identidad, muchos de ellos pueden hablar mapudungun, muchos de ellos pueden tener un conocimiento histórico, cultural súper bien, pero por ejemplo esa persona siempre va a hacer algo por el pueblo mapuche incluso dentro de su propia iglesia, o sea los animadores culturales por ejemplo que fueron un pilar fundamental para articular al pueblo mapuche en la dictadura.

En el caso de la iglesia católica, los centros bíblicos que potenciaron el mapudungun, el mapuche evangélico ha hecho aportes que no se les han considerado y justamente por esta idea errónea de pensar que estamos divididos, la división es una construcción colonial igual, porque quien dice que se está dividida, es lo occidental, el winka nos dice, 'no, ustedes están divididos' y lo creemos y lo reproducimos, nosotros estamos divididos, pero por lo que yo estoy apreciando en la historia y lo que estoy escribiendo, no veo esa división, o sea, yo veo mapuche de derecha que están cuestionando el gobierno militar, y veo mapuche de izquierda que actualmente están cuestionando a los jerarcas de los partidos que actualmente son la concertación en la época de los 80’ son sujetos mapuche que están cuestionando el colonialismo y eso para mí es la unidad entonces creo que esa idea de la unidad mapuche es una ficción que nos ha construido el colonizador, y que nosotros erróneamente lo reproducimos. 
Por qué todos los mapuche tienen que ser weichafe?; no sé, no creo que sea así; es como pedirle a los chilenos que todos sean milicos, irracional, y no por eso uno dice no hay unidad en el pueblo chileno; la unidad tú se la tañes a los mapuche y no le planteas la misma unidad a los chilenos; a los chilenos decirle "ustedes están desunidos porque ustedes tienen partido de izquierda y partidos de derecha, están desunidos"; no están desunidos, pero cuando se ve a un pueblo subalternizado si se les dice están desunidos, cuando tienen opciones de izquierda, derecha, cristiano, ateos, entonces eso es algo interesante en el juego y justamente eso es lo que estoy analizando con lo que estoy escribiendo, de decir que esta supuesta división es una ficción, no estamos divididos, hemos estado peleando contra el colonialismo estos 100 años y en eso no hay división lo que presentamos es una multiplicidad de estrategias y claro en algún momento lo unificaremos claro puede ser, unificaremos ciertos puntos, generaremos un marco de movilización en conjunto puede ser, pero creo que hay que colocar ojo, y hay que pensar desde donde vienen estos marcos, así como lo dividido, lo que es auténticamente mapuche, todos esos elementos que hoy en dia nos aparecen como naturales hay que revisarlos, hay que saber de donde salieron, esa es la pega que estoy haciendo y esa es la pega que comparto con otra gente mapuche.

\section{¿Se puede ser parte del proceso de descolonización y la vez tener vínculos con orgánicas institucionales chilenas?}

Por eso te recalcaba denante. Creo que en ese sentido, cualquier espacio que tu habrás para construir una correlación de fuerzas mapuche, para mi es viable, para mi es válido, el tema es para donde tú, como antiguamente uno decía, para donde tira el agua el molino, tira agua para mí o tira agua para otros, y creo que ahí es claro establecer, por ejemplo: ahora el partido se planteó una definición política que es un partido anticapitalista, que si bien muchos de nosotros somos de una posición anticapitalista, el partido no lo había tomado como decisión colectiva o no había estado dentro de la definición de la línea del partido, creo que una próxima definición del partido va a ser el tema colonial, vivimos en un situación colonial y nuestra política apunta a cuestionar esa situación colonial y dentro de ello el partido te permite a ti agruparte, accionar de manera política, te permite relacionarte con el poder y encarar al poder.

En ese sentido no le veo mayor contradicción; ahora eso no quiere decir que por estar dentro de un partido, uno está validando la relación colonial, o sea, en estos momentos necesitamos elementos que aglutinen, y dentro de esos elementos que aglutinen hay elementos que pueden aglutinar a una comunidad, pero hoy en día por ejemplo, y así lo muestra el censo, la mayoría de la gente no está en la comunidad, a esa gente como la agrupamos, en colectivos, en partidos políticos, 
creo que el partido es una opción para aglutinar a esa gente y también aglutinar a la gente digamos que pertenece a una comunidad, no veo mayor contradicción, es un elemento aglutinador, es un elemento político, y no es un fin, eso es lo otro importante, un partido jamás va a ser un fin, siempre va a ser un medio con lo cual tú te relaciones con el poder, de manera pacífica, o de manera también antagónica o violenta, los panteras negras eran un partido político, y fueron un partido que cuestionaron el poder estatal norteamericano y de hecho se enfrentaron a balazos con el FBI, de hecho les quemaron las sedes, llevaron presos, los mataron.

Un partido va a desarrollar su estructura dependiendo de los niveles y de acuerdo a las relaciones que en este caso el estado tenga con nuestra contraparte que es el pueblo mapuche, en el caso de la población negra, las relaciones fueron desde los aspectos más pacíficos como lo fueron las marchas por los derechos civiles, hasta la violencia que fueron las explosiones en revueltas, las explosiones que generaron las mismas panteras negras, toda esa tensión va a depender mucho de la contraparte en este caso, del estado chileno, el estado chileno aquí tiene mucho paño que cortar también. Pero como te digo un partido, el partido no hegemoniza al mundo mapuche, no hegemoniza ni al mundo mapuche ni al movimiento mapuche, es una opción más dentro de esta articulación, de este sistema de respuesta que yo te mencionaba, entonces eso es lo que yo veo en el caso del partido.

\section{Si hablamos de autonomía, que hacemos con los no mapuche dentro del territorio Mapuche.}

Mira ese es un tema que para mí no es complejo, porque el tema de la autonomía en el fondo es parte de una estructura administrativa. De hecho por ejemplo, las autonomías nacen en España, cuando cobran, en el fondo las autonomías nacen como para consolidar lógicas federales dentro de un estado y dentro de ellas pensar que una autonomía va a generar un proceso de limpieza étnica por decirlo así, es iluso, acá no estamos, no creo que estemos en un tema de vivencia racial que nos lleve a eso, no lo veo así, creo en los cogobiernos, de hecho, por ejemplo, cuando redactamos el epilogo del escucha winka! planteamos la idea del cogobierno, no nos planteamos la idea de un gobierno, y de hecho también el consejo de todas las tierras planteó lo mismo en su momento, la idea de cogobierno; hay algunos dirigentes que se han pasado hoy en día un poco más de revoluciones y hablan de un estado independiente, pero no creo, porque para llegar a un estado independiente, primero que no estamos en un región que no tiene una capacidad económica para sustentar un estado, primero que nada, de hecho tampoco, yo creo que realmente hay que trabajar con lo que realmente 
piense la gente mapuche común y corriente, la gente mapuche que vive el día a día, hay que pensar en esas aspiraciones en términos políticos.

Creo que si bien resulta más mediático el dicho revolucionario y todo eso, eso no deja de ser un slogan político, por ejemplo la Coordinadora Arauco Malleco hablo miles de veces, un discurso hablaba de autonomía otra de determinación, pero hasta el día de hoy no han levantado ninguna propuesta concreta ni de autonomía ni menos de como ejercer la autodeterminación, entonces creo que esa discusión es una construcción que tenemos que ir dándola con el tiempo, y como te digo, pensar o llegar a la idea de que se va a expulsar gente no mapuche, están casados, tiene pareja, hermosas familias, pese a que las relaciones coloniales son violentas, pero también las relaciones coloniales no son hegemónicas, hay un montón de espacios donde se desarrolla el amor, donde se desarrolla la convivencia, hay aspectos también dentro del mundo colonial, en la cual los sujetos, muchas veces prefieren relaciones coloniales porque les ofrece mejores garantías incluso, entonces también tenemos que discutir eso, o sea no es por nada que cuando se abren los juzgados muchos mapuche abarrotan los juzgados chilenos una vez que entra el ejército chileno y eso no es por casualidad, la sociedad mapuche no era una sociedad perfecta y tomo cosas del mundo winka apenas invadieron el país mapuche, y como respondemos a eso, también tenemos que tener claro que la gente no siempre se siente contento con su sociedad y quiere cambiar cosas y es válido es toda sociedad.

Ahora lo interesante es que dentro de eso exista, y por ello apelamos a la autodeterminación, que nosotros podamos decidir que integrar de la sociedad chilena de las sociedades globales, hay que mantener de nuestras propias sociedades, ahora como te digo claro, existen están posturas ultristas que son minoritarias también, y que también son insustentables porque tampoco buscan generar un consenso con la mayoría de los mapuche; aquí no podemos pensar que 20 comunidades en conflicto o 30 comunidades en conflicto van a hegemonizar el pensamiento de las 3000 comunidades que existen, o si la miramos en números concretos, ya digamos que 1000 personas, 1000 militantes mapuche, van a influenciar a un pueblo que es casi un millón de personas, o sea que es más de un millón de personas, no funciona así, y esa es una cuestión que muchas veces los sujetos que buscan las cámaras y que son más mediáticos no lo visibilizan, hay sujetos que ni siquiera representan a nadie y están dando opiniones políticas pero sin representar a nadie, ni siquiera a la persona mapuche que atiende un quiosco, $o$ por ultimo hablamos de un mapuche gerente, no lo puede sostener, entonces creo que esa construcción se va a dar en el tiempo, se va a dar en base a discusiones, se va a dar en base a que la gente comienza a plantear que es lo que ellos quieran. 
El movimiento mapuche tiene que empezar a trabajar bajo esa lógica, con pensar que es lo que la gente común y corriente quiere, hoy en día en todas las familias, hay familias emparentadas con winkas, y yo no creo que esa familia va a decidir por ejemplo en un referéndum que quieren que se vallan los winkas, no yo creo que van a apoyar a que se queden y que convivan, y si estamos hablando que es en todas las familias, estamos hablando que más de la mitad de los mapuche están emparejados con winkas, entonces claro aquí hay mucha descripción que construyen ciertos grupos pequeños que se toman la palabra, pero que no desarrollan ningún trabajo concreto hacia el resto del mundo mapuche, lo realizan en base a su comunidad, a su grupo de referencia, pero no hay una discusión amplia, y mi militancia en el fondo lleva a que esta discusión se amplia.

Si escribo es porque yo sé que el día de mañana me van a leer un montón de cabros mapuche que capaz que ya no estén ni siquiera vinculados con la comunidad, porque no sé, su bisabuelo se vino a vivir a Temuco, su bisabuelo se fue a vivir a Santiago y ahí ya perdieron todo el hilo, pero esos cabros no dejan de sentirse mapuche, y tienen derecho como mapuche a pensar su sociedad, y yo escribo para esa gente, escribo para el winka, entonces eso básicamente como te digo, creo que uno hace historia, trabaja historia, no es para que lo lea y por eso me diferencio de esa visión ideológica, porque a mí no me interese que me lea el militante, me interesa que me lea el no militante, y que esa persona que no es militante pueda opinar.

\section{¿Cuál es la estructura concreta de ese tipo de gobierno, en términos de construcción?}

Es complejo, la mayoría de las autonomías desarrollan una carta autonómica que en el fondo es una pequeña constitución, que está articulada a la constitución del Estado, por lo tanto, hay un marco digamos, un paragua legal, un pacto legal que está ahí, por otro lado, los poderes del Estado, se tienen que desarrollar a escala autonómica y eso implica tener un pequeño parlamento, y ahí las cuotas de poder son, si es cogobierno, hay cuotas de poder de por medio, en los aspectos judiciales también, y hay un ejecutivo, se elige al presidente de la comunidad autónoma, por lo tanto, esos son los aspectos básicos de cualquier autonomía.

La gracia de una autonomía es que descansa en el poder local, y por lo tanto, la gente conoce y convive con quien elige, es mucho más democrático, por lo tanto, hay un trabajo mucho más concreto políticamente, las autonomías se instalan de esa manera, por algo cuando una región es autonómica debe crearse por vías referéndum, en esta lógica autonómica, pero ellos ya están apostando a salir de la autonomía una cosa mucho más complejo que casi la independencia, pero en el 
fondo creo, se puede, se puede, pero va en que la gente común y corriente valla pensando que es la forma o el sistema que les permitiría vivir mejor, que les permitiría resolver mucho mejor sus problemas concretos, ósea, que no tengan que depender de Santiago para la pavimentación de poblaciones, que no tengan que depender de Santiago para mejorar la infraestructura de los recolectores de agua por ejemplo, una ciudad que se está inundando cada vez más, como Temuco, que pueda resolver acá dentro de la región los problemas de conurbación, o sea son temas que se pueden resolver más fácil acá en la región con mecanismos propios, que tengan que estar dependiendo de un Estado central, entonces creo que en ese sentido cuando la gente logre percibir de esa manera y que eso le sirve mejor la gente se va a empoderar de ese discurso.

\section{Conclusiones}

Hoy que los mapuche y sus movilizaciones están en el "ojo del huracán" mediáticamente, producto del juicio a los comuneros mapuche por la muerte del matrimonio Luchsinger Mackay, la quema masiva de camiones, iglesias cristianas, y la aplicación nuevamente de la ley antiterrorista por parte del gobierno de turno, es más que necesario poner en el centro de la mesa la discusión referida a la autonomía.

La palabra hilvanada por Sergio Caniuqueo desde su propia historia y la historia junto a otros y otras, hacen de la reflexión aquí presentada, un ejercicio analítico, político y cotidiano que permiten vislumbrar al menos tres nodos que permite al cierre de esta proposición, poner en relieve las proyecciones de este debate.

En primer lugar, la historia mapuche como sitio de estudios y controversias, desde ópticas chilenas y mapuche en su conjunto o por separado, es una elaboración que no solo es discursiva y política, sino que también es una referencia a lógicas propias de los pueblos indígenas y sus propias experiencias. En el caso mapuche de post ocupación militar, la emigración a las grandes ciudades, los procesos de proletarización y el peso de la asimilación son parte de un capítulo en el cual la autonomía como proyecto de liberación pareciese no ser parte de las certezas de dicho momento. No obstante, los procesos de resistencia mapuche en las ciudades, la resignificación de espacios, tiempos y sujetos es una arista que denotan una lógica que no es chilena; que el observador externo no entiende o no parece comprender. El idioma, la memoria y el sentido de la historia afloran entre los mapuche y así el escenario de la autonomía no deja de estar, a pesar del peso de la asimilación y el integracionismo. Hay algo más. En este sentido, Sergio Caniuqueo, lo expresa con claridad cuando se refiere a librera el conocimiento, hacerlo fluir. Las claves de esta instancia están ahí, y es necesario visibilizar y sistematizar. 
En segundo lugar, la crítica al colonialismo imperante es otro hilo que es prudente considerar en esta oportunidad. Caniuqueo es categórico. Dice que el discurso hegemónico chileno, winka indica él, presenta la realidad desde su prisma; en este sentido, lo mapuche es lo incorrecto; lo no adecuado; lo winka es coherente y lo adecuado. Sin duda que este punto es interpelado, pues remece la "naturalización" de lo cotidiano, de las ideas "de siempre". Eso es el colonialismo según este autor. Una evidencia que no debe notar que opera, pero opera, racializando y segregando a diario en ciudades, escuelas, universidades, comercio, etc.

En tercer lugar, cabe consignar lo dinámico del debate y la articulación de autonomía. En la reflexión de Sergio Caniuqueo, afloran cuatro aspectos relevantes: autonomía como proceso, como construcción, como ejercicio y como acción. De esta forma, el concepto central de esta propuesta se torna complejo, tenso y proyectual a la vez. Por un lado, un proceso histórico que para el caso mapuche puede registrar su punto de inicio con Aburto Panguilef iniciada la década de 1930; a partir de 1994 José Mariman se abre un debate acerca de posibilidades de autonomía que durante estos años se ha reabierto en la comisión de regionalización; como ejercicio político y social que se puede visualizar en el caminar del movimiento mapuche durante el siglo XX y lo que va de esta centuria, y por último, la autonomía como accionar en las comunidades y en las organizaciones urbanas que ponen como referencia de acción, la autonomía, el recuerdo del parlamento de Quillin y la memoria de Wallmapu pre reduccional.

Por último, consignemos que esta discusión histórica se construye día a día; no existen panaceas ni recetas infalibles; así tampoco existen comunidades que piensen estas consideraciones desde una sola perspectiva o prisma; lo que aquí se conjuga magistralmente son las miradas y lógicas de mundo desde lo social, político, económico, cultural en un conjunto que se conecta y tensa cada vez que la historia y "sus circunstancias", avanza en la temporalidad del tiempo y el espacio.

\section{Bibliografía}

ANCAN, José (1994). "Los urbanos: Un nuevo sector dentro de la sociedad mapuche contemporánea", Pentukun 1. Temuco: Instituto de Estudios Indígenas, Universidad de la Frontera.

ANTILEO, Enrique y ALVARADO, Claudio (2016). Santiago waria mew. Santiago: comunidad de historia mapuche. 
AÑINIIR, David (2009). Mapurbe/Venganza a raíz. Santiago: Pehuén ediciones.

CABRERA LLANCAQUEO, José (2014). Machi mongen tani Santiago warria mew. Santiago: Grupo de Trabajo Kuifike.

CANALES, Pedro (2014). Etno intelectualidades. Revista Aplha. N³9. Osorno: ULA.

CANALES, Pedro (2012). "Intelectualidad mapuche, problemáticas y desafíos. Conversación con el historiador José Marimán Quemenado". Revista Cuicuilco, Núm 63, México: Escuela Nacional de Antropología e Historia. 223-235.

CANALES, Pedro (2015). Historiografía Mapuche: balances y perspectivas de discusión en el Chile reciente. Conversación con Jorge Pinto Rodríguez. Revista Izquierdas $\mathrm{N}^{\circ} 24$. IDEA-USACH.

CANIUQUEO, Sergio (2006). El siglo XX en el Gulumapu: de la fragmentación del Wallmapu a la unidad nacional mapuche. 1880-1978. En Mariman, Pablo et al..!!! Escucha winka!!! Cuatro ensayos de historia nacional mapuche y un epilogo de futuro. Santiago: Lom.

CANIUQUEO, Sergio (2011). Reflexiones sobre el uso de la cultura como matriz cultural en el caso Mapuche. Algunas notas introductorias de principios del siglo XX. Revista Cuadernos interculturales. $\mathrm{N}^{\circ} 17$. UV.

CANIUQUEO, Sergio (2013). Reconfiguración del colonialismo. Revista historia social y de las mentalidades. $\mathrm{N}^{\circ} 17$. DPTO. HISTORIA. USACH.

CANIUQUEO, Sergio (2016). Tacum. El grupo de teatro de ad-Mapu. En Canales, Pedro. Zuamgenolu. Pueblo mapuche en contexto de estado nacional chileno. Siglos XIX-XX. Ediciones Usach. p. 181.

FANON, Frantz (2003). Los condenados de la tierra. México: Fondo Cultura Económica.

HUENCHIMILLA, Francisco (2017) Plurinacionalidad. El nuevo pacto. Santiago: Pehuén ediciones.

MARIMAN, José (2012). Autoderminación. Santiago: Ediciones Lom.

MARIMAN, Pablo et al (2006). iii... Escucha, winka...!!! Cuatro ensayos de historia nacional mapuche y un epilogo de futuro!!! Santiago: Ediciones Lom.

NAHUELPAN, Héctor. "Las “zonas grises" de las historias Mapuche”. Revista de Historia Social y las Mentalidades. N 17. Santiago: USACH. 2013. 9-31. 
PINTO, Jorge (2001). La Formación del estado y Pueblo Mapuche. De la inclusión a la exclusión. Santiago: IDEA-USACH.

RIVERA, Silvia (1986) Oprimidos, pero no vencidos. La Paz: La mirada salvaje.

TRICOT, Tito (2012). Autonomía. El Movimiento Mapuche de Resistencia. Santiago: Ceibo Ediciones.

ZAPATA, Claudia (2007). Los intelectuales indígenas piensan América Latina. Quito. Abya Yala. 